\title{
REDACTIONEEL
}

\section{Politiecultuur als kernbegrip en discussiethema}

\author{
Merlijn van Hulst, Jan Terpstra \& Emile Kolthoff
}

Vanaf de eerste empirische onderzoeken naar de politie, in de jaren zestig en zeventig van de vorige eeuw, heeft het concept politiecultuur een centrale plaats ingenomen in de politiewetenschap. Het vormde een sleutelbegrip in de eerste wetenschappelijke pogingen zicht te krijgen op het specifieke van de politieorganisatie, op het dagelijks reilen en zeilen daarvan, de achtergronden die daarbij een rol spelen en op de betekenissen die politiemensen aan hun werk gaven. Daarbij werd vooral gebruikgemaakt van intensief, etnografisch onderzoek. Niet alleen om een gedetailleerd beeld te krijgen van de dagelijkse praktijken van politiemensen op straat en binnen hun organisatie, maar ook om zicht te krijgen op de deels stilzwijgende en onderliggende waarden en zingeving die daaraan ten grondslag liggen (Skolnick 1966; Westley 1970; Rubenstein 1973; Van Maanen 1974). Tot op de dag van vandaag vormt het begrip politiecultuur een min of meer vast referentiekader waar vrijwel geen onderzoeker op dit terrein om heen lijkt te kunnen. Om die reden is het begrip door Sklansky (2007) omschreven als een onbetwiste orthodoxie.

Tegelijk is al vaker geconstateerd dat het begrip, evenals de wijze waarop het in veel gevallen wordt gehanteerd, een aantal vragen oproept (zie hiervoor onder meer Chan 1997; O’Neil Marks en Singh 2007; Terpstra 2009; Loftus 2009; Cockcroft 2013). Die vragen hebben zowel betrekking op de gehanteerde cultuurtheorie, als op de geloofwaardigheid en generaliseerbaarheid van bevindingen. Toch vormt het begrip politiecultuur steeds weer een inspiratiebron voor nieuw onderzoek naar politie en politiewerk. Voor onderzoekers blijft de vraag van groot belang welke min of meer gedeelde waarden, betekenissen, symbolen, rituelen en jargon (om maar enkele aspecten te noemen) de dagelijkse gang van zaken binnen de politieorganisatie kenmerken en deze organisatie haar in vele opzichten specifieke karakter geven. Daarbij wordt door onderzoekers ook geprobeerd tot dan toe ongebruikte wegen in te slaan, waarbij zij soms nieuwe onderwerpen aan de orde stellen, andere benaderingen of perspectieven uitproberen, eigen begrippen introduceren, maar verrassend vaak toch ook weer teruggrijpen op de klassieke werken op dit terrein en op de daarin genoemde thema's en ontwikkelde inzichten.

Nog niet lang geleden werd geconstateerd dat de term politiecultuur in Nederlands onderzoek (en de Nederlandse politiepraktijk) wel regelmatig werd gebruikt, maar dat gericht onderzoek naar de culturele aspecten van politie en politiewerk grotendeels ontbrak (Terpstra 2009). Nederlandse wetenschappelijke publicaties beperkten zich tot het vrij klakkeloos overnemen van lijstjes met cultuurkenmerken uit overigens vaak al oudere onderzoeken uit de VS en GrootBrittannië, zonder dat duidelijk was of deze wel op de situatie van de Nederlandse 
politie van toepassing zijn. Bovendien werd het begrip politiecultuur nogal eens als gelegenheidsargument of stoplap gebruikt om uiteenlopende en vooral als negatief beoordeelde verschijnselen bij de politie ad hoc van een 'verklaring' te voorzien. Punch (1985), die op basis van veldwerk in Amsterdam over politiecultuur schreef (Punch 1979, 184ff; zie ook Punch et al. 1999), merkte al eerder op dat er vaak een merkwaardig automatisme bestaat om uiteenlopende vormen van politiegedrag toe te schrijven aan 'de politiecultuur'. In veel gevallen dat dit gebeurt, is echter onduidelijk wat de empirische basis is van een dergelijke claim en of andere verklaringen niet meer op hun plaats zouden zijn. Voor zover in Nederlands onderzoek informatie is verzameld over politiecultuur, is dat vaak niet meer dan een 'bijvangst' van onderzoek dat primair is gericht op andere, meer praktische of beleidsmatige vragen (Terpstra 2009). Een systematische en diepgravende analyse van politiecultuur bleef daardoor vaak achterwege.

Inmiddels echter zijn er in Nederland meerdere studies verschenen die zich expliciet bezighouden met politieculturele verschijnselen. Het cultuurbegrip zelf staat in deze studies overigens niet per definitie centraal, maar het gaat wel degelijk over waarden, betekenis, symbolen en andere concepten en fenomenen die een nauw verband hebben met (politie)cultuur, dan wel een nadere specificatie van elementen van die cultuur inhouden. Daarbij worden nieuwe vragen opgeworpen en alternatieve benaderingen gehanteerd. Een aantal belangrijke studies wordt hier kort genoemd.

Terpstra en Schaap (2011, 2013), om te beginnen, kozen voor een op dit terrein ongebruikelijke kwantitatieve benadering om de tot dan toe geheel verwaarloosde vraag te beantwoorden in hoeverre de klassieke lijstjes met kenmerken van politiecultuur eigenlijk wel van toepassing zijn op de Nederlandse politie. Van Hulst (2013a, b) richtte zich in zijn studie op de verhalen die politiemensen elkaar voortdurend vertellen en waarmee zij betekenis geven aan hun werk. Landman (2015) ging in zijn proefschrift na welke patronen zijn te ontdekken in de betekenissen die politiemensen in hun werk hanteren en maakt duidelijk dat de concrete setting waarin zij zich op dat moment bevinden hierbij een doorslaggevende factor is. Çankaya (2011) liet in zijn onderzoek naar de positie van leden van etnische minderheden binnen de politieorganisatie zien dat door politiemensen als vanzelfsprekend gehanteerde 'normbeelden' direct en indirect kunnen bijdragen aan interne sociale uitsluiting. In een vervolgstudie ging dezelfde auteur in op de wijze waarop politiemensen bij proactief politiewerk beslissingen nemen en daarbij in belangrijke mate afgaan op de wijze waarop zij zich van verschillende typen burgers en situaties een beeld vormen (Çankaya 2012). In de studie van KleijerKool (2013) staat de vraag centraal hoe de Nederlandse politie reageert op de multiculturalisering van de samenleving. Zij probeert dat te begrijpen vanuit een spanningsveld tussen wat zij noemt het politiemanagementmodel en het politiewerkmodel. Deze modellen verschillen onder meer in de nadruk die wordt gelegd op (politie)culturele elementen. Mutsaers (2015) probeerde aan te geven hoe politiemensen hun discretionaire ruimte gebruiken in hun contacten met leden van etnische minderheden en zich daarbij zouden laten leiden door stereotypen en 
vooroordelen. Ook keek hij naar de wijze waarop etnische scheidslijnen binnen de politieorganisatie werken.

Duidelijk is dat met deze studies het thema van de politiecultuur in Nederland is verbreed en daarmee nadrukkelijk op de onderzoeksagenda is komen te staan. Dit themanummer van het Tijdschrift voor Veiligheid wil een bijdrage leveren aan deze ontwikkeling. Ter introductie op dit nummer wordt echter eerst een kort overzicht gegeven van onderzoek en theorie rond politiecultuur en van de belangrijkste discussies en perspectieven die op dit terrein de laatste decennia hebben gespeeld. Deze inleiding wordt afgesloten met een kort schets van de bijdragen die in dit nummer aan bod komen.

\section{Standaardbeeld van politiecultuur}

Cultuur van en in organisaties is een thema dat niet alleen door politieonderzoekers is bekeken. Vooral in de organisatiewetenschappen is het reeds lange tijd een onderzoeksthema. Een zeer invloedrijke opvatting over (beroeps- of organisatie)cultuur is onder meer verwoord door Schein (1985/2004). Bij cultuur gaat het bij hem om de onderliggende, min of meer stabiele en gedeelde basisaannames die een groep kenmerken. In dezelfde lijn omschrijft Manning (1977) politiecultuur, namelijk als de deels vanzelfsprekende en vaak informele 'kernvaardigheden, cognities en voorkeuren' van politiemensen, met name over wat 'goed' politiewerk is. Een nog wat ruimere opvatting is onder meer verwoord door Reiner $(2010,116)$ in zijn analyse van cop culture: het complexe samenspel van waarden, houdingen, symbolen, regels, voorschriften en praktijken die ontstaan in reactie op de eisen en situaties waarmee politiemensen in hun werk worden geconfronteerd en die door hen geïnterpreteerd worden met behulp van de cognitieve kaders en oriëntaties die zij, mede op basis van eerdere ervaringen, bezitten.

In de loop van de tijd is in de literatuur een 'standaardbeeld' of standaardmodel ontstaan van politiecultuur (Terpstra 2009; Terpstra en Schaap 2013; Van Hulst 2013b). De beschrijvende onderdelen van dit model bevatten een lijst van elementen die vaak als kenmerkend worden gezien voor de politiecultuur. Een bekend overzicht van deze kenmerken van politiecultuur is opgesteld door Reiner (2010, 118-132): het gedeelde besef met het werk een belangrijke missie te hebben, een sterke oriëntatie op actie en spanning in het werk, een zeker cynisme en pessimisme over de mogelijkheden de wereld te verbeteren en problemen afdoende op te lossen, wantrouwen tegenover mensen buiten de politie, in combinatie met een sociaal isolement van politiemensen en veel nadruk op onderlinge solidariteit, een cultus rond 'mannelijkheid', een zowel politiek als cultureel-maatschappelijk conservatisme en een anti-intellectueel pragmatisme. Vrij recent onderzoek (Terpstra en Schaap 2013) laat zien dat deze lijst met cultuurkenmerken niet zonder meer van toepassing is op de Nederlandse politie. Veel politiemensen werkzaam in de Nederlandse basispolitiezorg leggen, evenals hun collega's in de VS, in Engeland en in Wales, veel nadruk op de maatschappelijke opdracht van de politie, zijn sterk gericht op directe actie in hun werk, wantrou- 
wen vaak buitenstaanders en zijn van oordeel dat onderlinge solidariteit tussen collega's erg belangrijk is. Andere kenmerken komen onder Nederlandse politiemensen naar verhouding echter veel minder voor, zoals conservatisme of een sterke nadruk op mannelijke waarden.

\section{Kanttekeningen bij onderzoek}

In de loop van de tijd zijn vanuit verschillende perspectieven kritische kanttekeningen geplaatst bij het concept politiecultuur zoals dat in veel publicaties wordt gehanteerd (Terpstra 2009). Ten eerste is er door velen op gewezen dat van het begrip politiecultuur ten onrechte de suggestie uitgaat van een universeel verschijnsel. Verondersteld wordt dat de aard van het politiewerk overal ongeveer dezelfde is en overeenkomstige eisen en problemen met zich brengt. Daarom zou ook de politiecultuur in verschillende landen dezelfde kenmerken hebben. Uit een studie van Terpstra en Schaap $(2011,2013)$ blijkt echter dat deze veronderstellingen in zijn algemeenheid voor de Nederlandse situatie niet van toepassing zijn.

Daarnaast werd er ten onrechte lang van uitgegaan dat de politiecultuur binnen landen een min of meer homogeen verschijnsel zou zijn. Verschillende studies (Wilson 1968; Braun 1999) laten echter zien dat binnen de politieorganisatie verschillende subculturen naast elkaar kunnen bestaan. Sommigen hebben die lijn verder doorgetrokken door te laten zien dat er ook verschillende werkstijlen van individuele politiemensen zijn aan te wijzen (zie bijvoorbeeld Muir 1977; Van der Torre 1999; Çankaya 2012; Terpstra 2008; Van den Brink et al. 2015). In het verlengde hiervan richten veel publicaties over politiecultuur zich vooral op het meest zichtbare en traditionele deel van het politiewerk, namelijk de surveillancediensten en in wat mindere mate het wijkwerk, terwijl bijvoorbeeld de cultuur van beleidsmakers, criminaliteitsanalisten, ondersteunende diensten of van leidinggevenden veel minder of zelfs geen aandacht krijgen (Foster 2003).

De laatste jaren ontstaat ook belangstelling voor onderzoek naar culturele aspecten van recherchewerk. Innes (2003) laat zien hoe rechercheurs met behulp van onder meer verhoren, forensisch onderzoek en andere opsporingsmiddelen een 'verhaal' construeren waarmee zij zich een beeld vormen van de criminele gebeurtenis die zij onderzoeken en van de wijze waarop verschillende personen daarbij betrokken waren. Deze notie van een 'verhaallijn' vormt ook voor rechercheurs zelf een belangrijke notie in hun werk (De Poot et al. 2004). Door Hawk en Dabney (2014) is gewezen op het belang van frames in de opsporing. Dit uitgangspunt is verder uitgewerkt door Salet (2015). Zij laat aan de hand van onderzoek in grootschalige opsporingsteams zien dat enerzijds rechercheurs zich een beeld vormen van hun zaak met behulp van frames, maar dat zij er anderzijds moeite mee hebben ook op een andere wijze naar hun zaak te kijken, dat wil zeggen 'uit hun frame te stappen'.

De vraag in hoeverre de politiecultuur in de loop van de tijd is veranderd, is op verschillende wijzen beantwoord. Sommige auteurs hebben vooral gewezen op de veranderingen die zich over de afgelopen decennia hebben voorgedaan in onder 
meer de aard van het politiewerk, de samenwerking met andere organisaties en instellingen, het gebruik van nieuwe technologieën, en de komst van andere categorieën politiemensen (waaronder vrouwen, leden van etnische minderheidsgroeperingen en homo's) (zie bijvoorbeeld Paoline 2003; Punch 2007; Sklansky 2007). Gericht onderzoek naar de vraag in hoeverre daarmee ook werkelijk de politiecultuur is veranderd, lijkt er echter op te wijzen dat hier sprake is van een opvallende continuïteit (Loftus 2009).

Tot slot, een van de problemen op dit terrein is dat de overtuigingskracht van het beschikbare onderzoek soms te wensen overlaat. Dit is overigens niet een recent probleem. Ook bij klassiekers zijn op dit punt bij nadere beschouwing soms kanttekeningen te plaatsen. Zo volgt de vaak geciteerde conclusie van Reuss-Ianni (1983) dat binnen de politie twee subculturen zijn te onderscheiden, namelijk die van de management cops en van de street cops, strikt genomen niet uit haar studie, simpelweg omdat ze geen onderzoek deed onder management cops. ${ }^{1}$

\section{Theoretische vragen en discussies}

Rond het begrip politiecultuur zijn niet alleen vragen gerezen over de empirische basis en houdbaarheid van bepaalde veronderstellingen, maar ook over de vraag hoe het bestaan en voortbestaan van deze cultuur (homogeen of meer divers) kan worden begrepen. Opnieuw beperken wij ons hier tot enkele van de belangrijkste thema's die daarbij aan bod zijn gekomen. In veel gevallen wordt ervan uitgegaan, impliciet en soms ook expliciet, dat de politiecultuur moet worden begrepen vanuit de pogingen van politiemensen antwoorden te vinden op de spanningen die hun werk met zich meebrengt, zowel extern (bestaande uit gevaren en risico's op straat), als intern (gelegen vooral in de wijze van leidinggeven en sturing van hun werk) (Paoline 2003). Eerder is deze gedachtegang omschreven als een stresscopingmodel van de politiecultuur. Dit model wordt gebruikt niet alleen om te verklaren waarom politiecultuur bestaat, maar ook waarom de cultuur van de politie op verder zeer uiteenlopende locaties belangrijke overeenkomsten kent en een grote mate van duurzaamheid lijkt te bezitten (Terpstra 2009).

Hoewel er empirisch sterke aanwijzingen zijn voor een verband tussen enerzijds interne en externe dreigingen en risico's en anderzijds de mate waarin een traditionele politiecultuur wordt onderschreven (Terpstra en Schaap 2013), moeten er vanuit theoretisch perspectief toch belangrijke kanttekeningen worden geplaatst bij deze gedachtegang. Ten eerste, niet alleen zouden gevaar en dreiging kunnen bijdragen aan het ontstaan van politiecultuur, maar het omgekeerde kan ook worden verondersteld. De cultuur helpt ook te definiëren wat moet worden beschouwd als gevaar en kan ertoe bijdragen dat politiemensen dat juist opzoeken vanwege de behoefte aan actie en spanning in hun werk (Terpstra 2009). Bovendien suggereert het stress-copingmodel weliswaar een actieve bijdrage van politiemensen aan de (re)productie van hun cultuur, maar uiteindelijk nemen ze daar

1 Braun (1999) kwam overigens tot een vergelijkbare bevinding, overigens wel gebaseerd op (eigen) onderzoek. 
zelf een tamelijk passieve rol bij in (Chan 1997, 66-67; Shearing en Ericson 1991). Ook levert het model empirisch een probleem op, aangezien er naast overeenkomsten en duurzaamheid, zoals gezegd ook verschillen en verandering in cultuur kunnen worden geconstateerd.

Een belangrijke uitwerking van een meer dynamische kijk op politiecultuur is begin jaren negentig gegeven door Shearing en Ericson (1991). Zij verzetten zich in hun analyse tegen de opvatting dat cultuur moet worden beschouwd als een set van (impliciete) regels die politiemensen in hun hoofd hebben zitten en die hun handelen bepaalt. Als alternatief voor een deterministische visie stelden zij een benadering voor waarin meer recht wordt gedaan aan cultuur als actief proces van betekenisgeving. Volgens Shearing en Ericson is politiecultuur geen mentale programmering, maar is zij eerder terug te vinden in de verhalen die politiemensen elkaar vertellen. Op deze wijze wordt de werking van politiecultuur niet meer begrepen als het volgen van informele regels en voorschriften, maar als een constante, actieve productie en reproductie van betekenis, en daarmee ook van verandering en aanpassing van de cultuur door politiemensen.

Enige jaren later leverde Waddington (1999) een belangrijke bijdrage aan onderzoek en theorie met betrekking tot politiecultuur. Zijn analyse begint bij de constatering dat veel onderzoek naar politiecultuur vooral betrekking heeft op wat politiemensen elkaar of een onderzoeker vertellen. In feite wordt de politiecultuur daarmee vaak gereduceerd tot wat hij in navolging van Fielding (1994) 'de kantinecultuur' van politiemensen noemt. Deze bestaat vooral uit verhalen die politiemensen elkaar vertellen. Deze notie is belangrijk, omdat er in de praktijk een aanzienlijk verschil kan bestaan tussen wat politiemensen in de kantine en op andere plekken zeggen over politiewerk en wat zij op straat in feite doen. Deze discrepantie komt bijvoorbeeld sterk naar voren in de studie van Björk (2008) onder politiemensen in Götenburg. Zij waren in hun onderlinge verhalen uitermate cynisch en negatief over de groepen burgers waarmee zij in hun werk te maken hebben, terwijl zij op straat vaak een opstelling bleken te hebben die eerder getuigde van betrokkenheid en medemenselijkheid.

In de opvatting van Waddington moeten de verhalen die politiemensen elkaar vertellen worden gezien als een reactie op de frustraties die zij in hun werk ontwikkelen. Zij hebben vaak een (wens)beeld van politiewerk als spannend en vol actie, maar in de sleur van alledag komt daar vaak weinig van terecht. Daar overheersen vaak eerder verveling en het wachten op een melding. De kantine wordt de plek om het beroep te vieren en hierbij worden zelden optredende, maar belangrijk geachte gebeurtenissen (bijvoorbeeld een arrestatie na een heldhaftige achtervolging) centraal gesteld. In zijn studie van politieverhalen en het vertellen daarvan liet Van Hulst (2013a, b) zien dat deze interpretatie van Waddington te beperkt is. Politieverhalen proberen niet slechts een beeld te schetsen van het politievak als stoer, hard en mannelijk. Het uitwisselen van verhalen door politiemensen dient ook heel andere functies, waaronder het delen van ervaringen op straat, het informeel leren van elkaar, het bespreken van bijzondere situaties waarop het goed is alert te zijn of het luisteren naar elkaars vervelende ervaringen op straat vanwege bijvoorbeeld belediging, bedreiging of geweld, maar ook als 
men betrokken raakte bij dramatische gebeurtenissen zoals een dodelijk ongeval of een verdrinking (zie ook Terpstra 2008).

\section{Oude vragen en nieuwe wegen}

Het verschijnsel politiecultuur blijft voor onderzoekers een uitdagend thema. Hoewel de klassieke studies over dit onderwerp belangrijk en invloedrijk waren en nog steeds zijn, dit onderwerp blijft toch op de onderzoeksagenda staan. Verschillende omstandigheden spelen daarbij een rol. Ten eerste, maatschappelijke ontwikkelingen maken dat zich rond de organisatie en het functioneren van de politie telkens weer nieuwe problemen en vraagstukken voordoen. De huidige discussie in Nederland rond etnisch profileren is daarvan een voorbeeld (zie bijvoorbeeld de studies van Svensson, Sollie en Saharso 2011 en van Van Leun et al. 2014). Ook in onderzoek naar deze thematiek wordt soms gekeken naar culturele factoren om na te gaan in hoeverre deze een verklaring kunnen bieden voor het politieoptreden ten aanzien van leden van etnische minderheidsgroeperingen (Çankaya 2012; Mutsaers 2015). Overigens lijken politieke factoren en de belangstelling van de massamedia van grote invloed te zijn of nieuwe ontwikkelingen ook tot onderzoek leiden. Zo is er nog nauwelijks onderzoek in Nederland naar de culturele aspecten van de groei van het aantal vrouwen en homoseksuelen binnen de politie. Weinig aandacht is in onderzoek ook besteed aan de culturele gevolgen van het groeiende belang van hoogwaardige technologische kennis en de afhankelijkheid van complexe informatiesystemen (en daarmee van de komst van steeds meer hoger opgeleiden met een niet-politieachtergrond). Mogelijk dat ook een instrumentele oriëntatie van opdrachtgevers, maar wellicht ook van onderzoekers zelf, hierbij een rol speelt.

Daarnaast blijven de klassieke vragen en thema's van belang die al in de oudere onderzoeken aan bod kwamen. Deels is dat omdat lang niet altijd duidelijk is wat de betekenis en relevantie zijn van de inzichten en uitkomsten uit deze studies voor de huidige situatie, ook in Nederland. Belangrijk zijn hiernaast vragen over overeenkomsten en verschillen binnen en tussen politieculturen. Ook zijn vergelijkingen met andere organisaties interessant (Loyens 2009; Terpstra 2016). Vervolgens blijven methodische en theoretische beperkingen van eerdere onderzoeken naar politiecultuur vragen om aandacht voor deze onderwerpen. De genoemde discussie over de actieve bijdrage van politiemensen aan de vorming van waarden, symbolen en betekenissen (Shearing en Ericson 1991) en de spanning tussen politiepraat in de kantine en politieactie op straat (Waddington 1999) zijn hiervan een voorbeeld. Cultuur kan hierbij als een voortgaand proces van betekenisgeving worden begrepen. In een poging tot theoretische en methodologische innovatie te komen op dit punt, zou politieonderzoek een voorbeeld kunnen nemen aan onderzoek in de organisatiewetenschappen. Het homogeniserende perspectief op organisatiecultuur van onderzoekers zoals de eerder genoemde Schein (1985) is in dit vakgebied niet alleen al vroeg een punt van discussie geweest (bijv. Gregory 1983; Martin 1992), het vakgebied heeft ook een aantal nieuwe stromingen voortgebracht die het culturele perspectief vernieuwen, 
aanvullen, specificeren en zelfs vervangen. We denken hierbij aan onderzoek naar sense-making (betekenisgeving) (bijv. Weick 1995), identiteit in organisaties (bijvoorbeeld Ybema et al. 2009) en nog meer ambitieuze stromingen zoals die van procestheorie (Langley et al. 2013) en onderzoek dat start vanuit organisatiepraktijken (Nicolini 2013).

In het verlengde hiervan is er nog een derde reden waarom onderzoek naar politiecultuur van belang blijft. Door uiteenlopende ontwikkelingen hebben waarden, symbolen en betekenissen veel van hun vanzelfsprekendheid verloren. In een meer reflexief georiënteerde samenleving (Giddens 1991) zijn deze in toenemende mate afhankelijk geworden van individuele keuzes, al dan niet in groepsverband. Dit geldt ook voor de politieorganisatie. Zo zijn zeker binnen de Nederlandse politie medewerkers individueel of in groepsverband, georganiseerd of op meer losse en toevallige basis, bezig met de vraag wat voor hen zinvol werk is, hoe zij dit werk 'betekenisvol' kunnen maken en wat voor hen (soms ook als zeer persoonlijk opgevatte vraag) 'goed politiewerk' inhoudt (Nap 2012). Ook vanuit dit perspectief is onderzoek naar de cultuur van politie en politiewerk van belang. Het is daarbij overigens wel nodig onderscheid te blijven maken tussen de verschillende invullingen die begrippen als 'betekenis' en 'betekenisvol' krijgen in de politie en in de wetenschap. Voor politiemensen staat 'betekenisvol' in de regel gelijk aan 'goed' of 'waardevol', voor wetenschappelijk onderzoekers is betekenisgeving daarentegen een neutraal begrip. Vanuit dit laatste perspectief kan de betekenis die politiemensen aan hun werk geven ook negatief zijn, zoals het geval is bij politiemensen die cynisch in hun werk staan en daarover fatalistische opvattingen hebben (zie ook Douglas 1982).

\section{Bijdragen aan dit themanummer}

In dit nummer van het Tijdschrift voor Veiligheid komen verschillende bijdragen aan bod die handelen over verschillende aspecten van politiecultuur. Deze bijdragen keren deels terug naar vragen die reeds naar voren kwamen in de klassieke studies naar politiecultuur. Voor een deel gaat het echter ook om nieuwe thema's, die door uiteenlopende veranderingen in en rond de politie de aandacht van onderzoekers vragen. In al deze bijdragen wordt ook geprobeerd een of meer antwoorden te vinden op eerdere kritieken die het gebruik van de term politiecultuur opriep. Zo wordt geprobeerd de soms veronderstelde homogeniteit van politiecultuur te vermijden door aandacht te geven aan verschillende normbeelden, wordt de aandacht gericht niet op de negatieve, maar juist op de positieve krachten van politiecultuur, wordt een oplossing geboden voor het door Waddington (1999) gesignaleerde probleem van het verschil tussen kantinecultuur en politiepraktijk, wordt de diversiteit in de politiecultuur tussen verschillende typen locaties (zoals tussen stad en platteland) benadrukt, wordt nagegaan hoe de gemediatiseerde beelden over de politie doordringen in de door politiemensen gehanteerde betekenissen. Daarmee wordt deels aangesloten bij internationale wetenschappelijke debatten over politiecultuur. 
De eerste bijdrage is van de hand van Sinan Çankaya. Hij pleit voor het gebruik van de notie 'normbeelden' in plaats van het begrip 'politiecultuur' om daarmee meer recht te doen aan de weerbarstigheid van de politiewereld. Normbeelden vormen volgens de auteur een analytische meerwaarde, omdat (1) de ideaalbeelden reeds zijn verbonden met het rechtstatelijke karakter van de politie, (2) de normbeelden voldoende analytisch flexibel zijn voor een situationele en relationele interpretatie van de culturele processen binnen de politieorganisatie, en (3) in de notie reeds het verzet van actoren tegen de normbeelden is besloten. Het artikel illustreert deze theoretische meerwaarde door te focussen op de dominante normen van de 'integere', 'neutrale' en 'loyale' politieagent.

In de bijdrage van Merlijn van Hulst, Gabriël van den Brink, Wiljan Hendrikx, Nicole Maalsté en Bas Mali draait het om de krachten die inwerken op politiemensen op straat en die hen helpen om betekenis te geven aan en in hun werk. Gebaseerd op eigen onderzoek in een aantal politie-eenheden komen de auteurs tot vier dimensies vanwaaruit krachten inwerken op politiemensen: omgeving en publiek, groepscultuur, leiding en organisatie, en persoonlijke factoren. Het onderzoek bevestigt eerdere bevindingen ten aanzien van de verschillende dimensies, maar laat ook zien dat er verschuivingen in de tijd plaatsvinden.

Wouter Landman maakt vervolgens aan de hand van veldwerk in twee basisteams de doorwerking van politiecultuur op politieoptreden zichtbaar. Hieruit komt naar voren dat politiecultuur zowel van invloed is op als een reactie is op het optreden van politieagenten. Een meerdimensionaal perspectief op de relatie tussen politiecultuur en politieoptreden is volgens Landman van belang en hij pleit voor verrijking van de kennis over politiecultuur door minder in tegenstellingen te denken (of/of-perspectief) en meer te zoeken naar waar synthese mogelijk is (en/en-perspectief).

De bijdrage van Jan Terpstra richt zich op de cultuur van de politie in landelijke gebieden. Dit gebeurt door de verhalen van politiemensen op het platteland te analyseren. Het laat zien dat in deze verhalen enkele elementen telkens terugkeren. Kernelement daarbij is het geconstrueerde contrast met een verbeelde stedelijke politie. Politiemensen op het platteland hebben vaak het gevoel als tweederangspolitie te worden gezien en behandeld. Daar stellen zij in hun verhalen een beeld tegenover van een politie die juist competenter is en betere methoden hanteert dan de stedelijke politie, met minder geweld en escalatie. Met deze verhalen construeren de politiemensen een identiteit van de plattelandspolitie.

In de laatste bijdrage aan dit themanummer over politiecultuur gaan Lianne Kleijer-Kool en Janine Janssen in op de mediale verbeelding van politiewerk en criminaliteit en de relatie tussen die twee. Hoewel we uit vele studies weten dat het meeste politiewerk niet over criminaliteit en opsporing gaat, houden de media het beeld van boeven vangen en snelle actie hoog. En zij niet alleen, ook politiemensen 'sensationaliseren' hun werk, zo betogen de auteurs. Als politiecultuur constructivistisch wordt opgevat, dient volgens hen ook gekeken te worden 
naar de mediale verbeelding van 'de politie', 'de boef' en hoe politiemensen hier zelf betekenis aan geven.

\section{Literatuur}

Björk, M. (2008) Fighting Cynicism Some Reflections on Self-Motivation in Police Work. Police quarterly, 11(1), 88-101.

Braun, D. (1999) Sturingsperikelen in de politieorganisatie. Een verkennende antropologische studie. Amsterdam: VU (diss.).

Brink, G. van den, W-J. Hendrikx, M.J. van Hulst, N. Maalsté en B. Mali (2015) Een onderzoek naar de morele weerbaarheid van Nederlandse politiefunctionarissen. Den Haag: Boom/Lemma.

Çankaya, S. (2011) Buiten veiliger dan binnen. Delft: Eburon.

Çankaya, S. (2012) De controle van marsmannetjes \& ander schorriemorrie: beslissingsproces tijdens proactief politiewerk. Den Haag: Boom Lemma.

Chan, J.B. (1997) Changing police culture: Policing in a multicultural society. Cambridge: Cambridge University Press.

Cockcroft, T. (2013) Police culture: themes and concepts. London: Routledge.

Douglas, M. (1982) In the active voice. London/Boston: Routledge and Kegan Paul.

Fielding, N.G. (1994) Cop Canteen Culture. In T. Newburn en E. Stanko (Ed.), Just Boys Doing Business: Men, Masculinity and Crime. London: Routledge.

Foster, J. (2003) Police Cultures. In T. Newburn (Ed.), Handbook of Policing. Cullompton: Willan.

Giddens, A. (1991) Modernity and self-identity: Self and society in the late modern age. Stanford: Stanford University Press.

Gregory, K.L. (1983) Native-view paradigms: Multiple cultures and culture conflicts in organizations. Administrative science quarterly, 359-376.

Hawk, S.R. en D.A. Dabney (2014) Are all cases treated equal? Using Goffman's frame analysis to understand how homicide detectives orient to their work. British Journal of Criminology, 54(6), 1129-1147.

Hulst, M.J. van (2013a) Storytelling at the police station: The canteen culture revisited. British Journal of Criminology, 53 (4), 624-642.

Hulst, M.J. van (2013b) Politieverhalen: Een etnografie van een belangrijk aspect van politieculturen. Politiewetenschap 66. Den Haag: Reed Business.

Innes, M. (2003) Investigating Murder. Detective work and the police response to criminal homicide. Oxford: Oxford University Press.

Kleijer-Kool, D. (2013) Multicultureel Politiewerk. Den Haag: Boom Lemma.

Landman, W. (2015) Blauwe patronen: betekenisgeving in politiewerk. Den Haag: Boom.

Langley, A., C. Smallman, H. Tsoukas en A.H. van de Ven (2013) Process studies of change in organization and management: Unveiling temporality, activity, and flow. Academy of Management Journal, 56(1), 1-13.

Leun, J.P. van et al. (2014) Etnisch profileren in Den Haag? Een verkennend onderzoek naar beslissingen op straat. Leiden: Universiteit Leiden, Faculteit Rechtsgeleerdheid, Afdeling Criminologie.

Loftus, B. (2009) Police culture in a changing world. Oxford: Oxford University Press.

Loyens, K. (2009) Occupational culture in policing reviewed: a comparison of values in the public and private police. Intl Journal of Public Administration, 32(6), 461-490.

Manning, P.K. (1977) Police Work: The social organization of policing. Cambridge (Mass.): The MIT Press. 
Martin, J. (1992) Cultures in Organizations: Three Perspectives. Oxford: Oxford University Press.

Muir, W.K.M. (1977) Police: Streetcorner Politicians. Chicago, IL: University of Chicago Press.

Mutsaers, P. (2015) A public anthropology of policing: Law enforcement and migrants in the Netherlands. Tilburg: Tilburg University.

Nap, J.A. (2012) Vragen naar goed politiewerk: belang-stellend ontwikkelen van de alledaagse praktijk. Een proeve van normatieve professionalisering. Den Haag: Boom.

Nicolini, D. (2012) Practice theory, work, and organization: An introduction. Oxford: Oxford University Press.

O’Neill, M., M. Marks en A.M. Singh (Eds.) (2007) Police Occupational Culture: New Debates and Directions. Oxford: Elsevier.

Paoline III, E.W. (2003) Taking Stock: Toward a Richer Understanding of Police Culture. Journal of Criminal Justice, 31, 199-214.

Poot, C.J. de et al. (2004) Rechercheportret. Over dilemma's in de opsporing. Alphen aan den Rijn: Kluwer.

Punch, M. (1979) Policing the Inner City. London: Macmillan.

Punch, M. (2007) Cops with honours: university education and police culture. In M. O'Neil, M. Marks en A.M. Singh (Eds.), Police Occupational Culture: New debates and directions, Amsterdam: Elsevier JAI, 105-128.

Punch, M., P. Tieleman en A.H. van den Bergh (1999) Politiecultuur. In C.J.C.F. Fijnaut, E.R. Muller en U. Rosenthal (red.), Politie: studies over haar werking en organisatie. Alphen aan den Rijn: Samsom.

Reiner, R. (2010) The Politics of the Police. Oxford: Oxford University Press (4th ed.).

Reuss-Ianni, E. (1983) Two Cultures of Policing. New Jersey: Transaction Publishers.

Rubinstein, J. (1973) City Police. New York, NY: Ballantine Books.

Salet, R. (2015) Opsporing, tegenspraak en veranderende frames. Een onderzoek naar tegenspraak in grootschalige rechercheonderzoeken. Den Haag: Boom Lemma.

Schein, E.H. (1985) Organizational Culture and Leadership. San Francisco: Jossey-Bass Inc.

Shearing, C.D. en R.V. Ericson (1991) Culture as Figurative Action. British Journal of Sociology, 42, 481-506.

Sklansky, D.A. (2007) Seeing blue: Police reform, occupational culture, and cognitive burnin. In M. O'Neill, M. Marks en A.M. Singh (Eds.), Police Occupational Culture: New Debates and Directions. Oxford: Elsevier, 19-45.

Skolnick, J.H. (1966) Justice without Trial: Law Enforcement in Democratic Society. New York, NY: Macmillan.

Svensson, J., H. Sollie en S. Saharso (2011) Proactief handhaven en gelijk handelen. Apeldoorn: Politie \& Wetenschap.

Terpstra, J. (2008) Wijkagenten en hun dagelijks werk. Apeldoorn: Politie \& Wetenschap.

Terpstra, J. (2009) Politiecultuur en politiepraktijken: empirische en theoretische kanttekeningen bij een kernbegrip. In G. Meershoek (red.), Politiestudies: terugblik en vooruitzicht. Een bundel essays voor Kees van der Vijver. Dordrecht: SMVP.

Terpstra, J. (2016) Occupational culture of private security officers in the Netherlands. Comparison with police officers' culture. Policing \& Society: An international journal of research \& policy, 26/1, 77-96.

Terpstra, J. en D. Schaap (2011) Politiecultuur: een empirische verkenning in de Nederlandse context. Proces, 90(4), 183-196.

Terpstra, J. en D. Schaap (2013) Police culture, stress conditions and working styles. European journal of criminology, 10(1), 59-73. 
Torre, E.J. van der (1999) Politiewerk. Politiestijlen, community policing, professionalisme. Alphen aan den Rijn: Samsom.

Van Maanen, J. (1974) Working the Street, a Developmental View of Police Behavior. In H. Jacobs (Ed.), The Potential for Reform of Criminal Justice. Beverly Hills, CA: Sage.

Waddington, P.A.J. (1999) Police (Canteen) Sub-Culture: An Appreciation. British Journal of Criminology, 39, 287-309.

Weick, K. (1995) Sensemaking in organizations. London: Sage Publications.

Westley, W. (1970) Violence and the police: a sociological study of law, custom and morality. Cambridge, MA: MIT.

Wilson, J.Q. (1968) Varieties of police behavior: the management of law and order in eight communities. Cambridge, MA: Harvard University Press.

Ybema, S., T. Keenoy, C. Oswick, A. Beverungen, N. Ellis en I. Sabelis (2009) Articulating identities. Human Relations, 62(3), 299-322. 